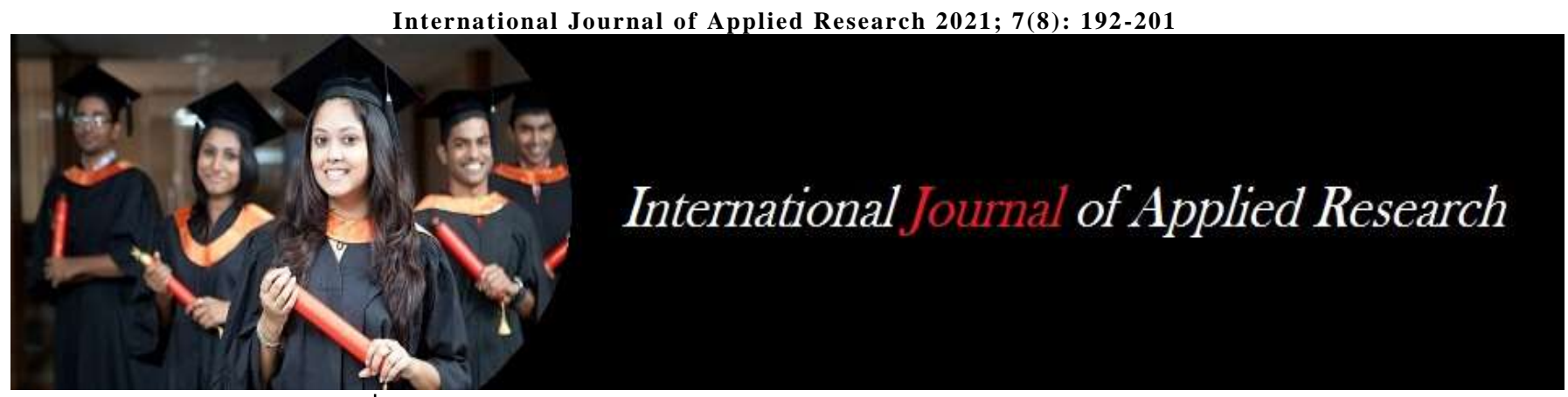

ISSN Print: 2394-7500 ISSN Online: 2394-5869 Impact Factor: 8.4 IJAR 2021; 7(8): 192-201 www.allresearchjournal.com Received: 23-06-2021 Accepted: 25-07-2021

Dhwani Topiwala Intern, PES Modern College of Physiotherapy, Pune, Maharashtra, India

Dr. Sonal Patole Assistant Professor, PES Modern College of Physiotherapy, Pune, Maharashtra, India

Dr. Sucheta Golhar Principal, PES Modern College of Physiotherapy, Pune,

Maharashtra, India

Dr. Trupti Ranglani Masters of Musculoskeletal Physiotherapy, Consulting physiotherapist at QI Spine Aundh, Pune, India
Corresponding Author: Dhwani Topiwala Intern, PES Modern College of Physiotherapy, Pune, Maharashtra, India

\section{Effectiveness of sprint interval training on repeated sprint ability (RSA) and lower limb power in amateur cricket batsmen at the end of 4 weeks: An experimental study}

\author{
Dhwani Topiwala, Dr. Sonal Patole, Dr. Sucheta Golhar and Dr. Trupti \\ Ranglani
}

DOI: https://doi.org/10.22271/allresearch.2021.v7.i8c.8863

\begin{abstract}
Purpose: Cricket necessitates intermittent activities, which include high intensity sprinting. Stop and go nature of the sprinting between the wickets puts stress on the cricketers. Batting requires the ability to run between the wickets effectively to increase the scoring rate. RSA is the capability of an athlete to recover \& maintain highest possible efforts during subsequent sprinting. Which is important in team sport. It is frequently trained \& calculated via high-intensity sprint, interspersed with brief recovery bouts $(<=30 \mathrm{sec})$. Sprint interval training works on developing metabolic or neuromuscular system or both. This research studies the effect of sprint interval training on repeated sprint ability and lower limb power in cricket batsmen.

Method: In this study 34 samples were collected according to the inclusion and the exclusion criteria. They were divided into two groups odd and even basis. Exercise protocol was administered to group A for 4 weeks, alternate days in each week and group B continued with their regular training. Pre and post data was collected using Repeated Sprint Ability test and Standing Long Jump test.

Results: After 4 weeks Results showed that in group A Sprint Interval Training has significant effect of Repeated Sprint Ability (Difference 6.193 to 5.186, $\mathrm{t}=5.085, \mathrm{P}$ value is 0.000 ) and Standing long jump (Difference 228.18 to $234.06, \mathrm{t}=9.017, \mathrm{P}$ value is $<0.0001$ ). After 4 weeks conventional exercise in group B didn't show enough significant effect on Repeated Sprint Ability (Difference 6.855 to 6.549, $\mathrm{t}$ $=0.5741, \mathrm{P}$ value is 0.5739 ) conventional exercises showed significant effect on Standing Long Jump test (Difference 197.53 to 199.29, $\mathrm{t}=3.017$, $\mathrm{P}$ value is 0.0082 ). Comparing group $\mathrm{A}$ and group $\mathrm{B}$, results showed that Sprint interval Training had significant improvements in improving the Repeated Sprint Ability (Difference 5.183 and $6.549, \mathrm{t}=3.061$, P value is 0.0044 ) and Standing Long Jump test (Difference 234.06 and 199.29, $\mathrm{t}=4.007$, $\mathrm{P}$ value is 0.0003 ) than conventional exercises.

Conclusion: This study concludes that Sprint Interval Training is more effective than conventional exercises in improving the repeated sprint ability and lower limb power in amateur cricket batsmen by the end of 4 weeks.
\end{abstract}

Keywords: Cricket, repeated sprint ability, power, sports physiotherapy

\section{Introduction}

Recently, the International Cricket Council has recognized more than 100 countries leading to cricket becoming a multimillion sport. An increase in interest in the game has been seen due to high level international competitions and tournaments. Different match formats of cricket, various specialist positions, and the eclectic environment it is often played in require players to be able to cope with a broad continuum of physiologic playing intensities. Introduction of the shorter, more intense formats of the game like T-20 and one day cricket, the idea of cricket as a leisurely activity is perhaps disingenuous ${ }^{[2]}$.

Cricket is played between two teams on a field and the center of which is a 22 meter pitch. Wickets are placed at both the ends of the pitch. Intermittent activities like batting, bowling fielding, the ability to move quickly \& powerfully is of great interest to those who involve with game ${ }^{[5]}$. In cricket batting, running between the wickets is very important task ${ }^{[2]}$. Start and stop nature of the sprinting between the wickets puts stress on the cricketers ${ }^{[5]}$. 
Batting requires the ability to run between the wickets effectively. An increase in scoring rate is seen with effective running between the wickets, which allows batsmen to get full value for their shots while batting. There is a need for batsmen to maximize scoring in popular shorter formats of the game like T-20 cricket and one day cricket. Batsmen take greater risks to increase the run scoring rate due to limited availability of overs in formats like T-20 ${ }^{[15]}$, and run between the wickets as an attempt to score the most. ${ }^{17}$ Cricket batsmen need when running between the wickets, cricket batsmen require to achieve high velocity as soon as possible as the sprints occur over relatively short distances (i.e. the length of a cricket pitch. Batsmen must be able to decelerate effectively so that they can place the bat within the crease, turn, and continue running towards the opposing crease in an effort to score maximum number of runs in one go ${ }^{[15]}$. This gives a powerful finish to the run a three, and reduces the chances of a run out ${ }^{[15]}$.

Batsmen are found having less sprinting ability as compared to bowlers according to previous study hypothesis. ${ }^{2}$ Cricketand strength and conditioning coaches should ensure that their players can achieve high sprinting velocities over the distances required to run in between the wickets while batting as suggested by some studies ${ }^{[15]}$. Frequent 6 seconds repeated sprint session there shown to be better to high intensity aerobic training in junior soccer players according to few studies ${ }^{[14]}$. 30 seconds sprint speed has shown innovative method to show rapid changes in exercise capacity and skeletal muscle endurance according to studies [14]. Adding to sport-specific technical and tactical skills, speed, cardiorespiratory fitness and repeated sprint ability (RSA) have been suggested to be vital components leading to success in many team sports ${ }^{[1]}$.

The ability to develop maximal speed is related to Repeated Sprint Ability (RSA) ${ }^{[3]}$.

RSA: explains the capability of an athlete to recover \& maintain highest possible efforts during subsequent sprinting, a characteristic regarded important in team sport.

It is frequently trained \& calculated via high-intensity sprint, interspersed with brief recovery bouts $(<=30 \mathrm{sec}){ }^{[3]}$. A complex training strategy that works on developing the neuromuscular or the metabolic system or both is known as Sprint interval training (SIT) ${ }^{[4]}$.

The high efficiency of this type of training is possibly an outcome of high simultaneous stress on both the anaerobic and aerobic energy systems ${ }^{[8]}$. Sprint interval training has been shown to improve neural adaptations and increase muscle $\mathrm{Cr}$ and $\mathrm{CK}$ levels, with simultaneous improvements in muscular oxidative capacity, muscle glycogen content, as well as enhanced muscle buffer capacity over a short span of time $[9,10]$, which are all factors likely to benefit the maintenance of high-intensity exercise ${ }^{[8,1]}$.

It is very important to produce great force/power and generate high velocity in the block and acceleration power in the initial phase of the sprint run ${ }^{[13]}$.

An important role is played by the game which involve sprinting \& stop and go movement during which the capacity to generate maximum force short burst of anaerobic power ${ }^{[21]}$ Along a continuum of exercise bioenergetics, the body's energy transfers system can be viewed. Most of the energy for fast movements and during increased resistance to movement at a given speed is provided by anaerobic sources ${ }^{[21]}$.

Operational definition: An amateur cricket player is a player lacking in experience and competence in the sport.
Power is the rate of doing work, i.e. the amount of energy transferred or converted per unit time.

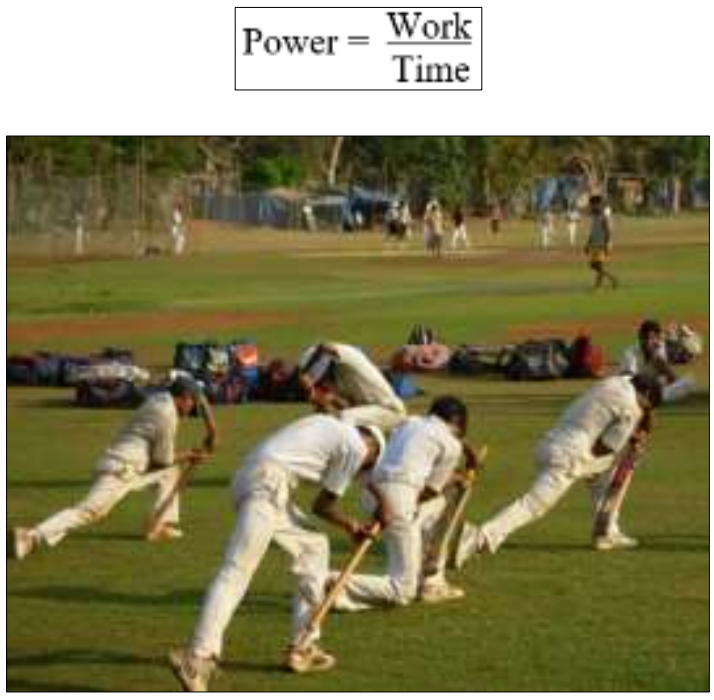

Fig: Cricket practice

\section{Need for study}

- Due to the nature of the game, cricket necessitates intermittent activities ${ }^{1}$ it has episodes of high intensity sprints and that's the characteristics of the game ${ }^{[2]}$.

- The batsmen has positional importance and hence it is necessary for them to have sprint speed ${ }^{[2]}$.

- While comparing to the elite batsmen when taught pacing they have better sprint performance than the untrained hence it's necessary to train amateur batsmen because they do not have subconscious control ${ }^{[6]}$.

- In the previous studies of soccer and tennis it's shown that the sprint interval training has positive effect on increasing the RSA ${ }^{[11]}$.

- Bowlers are found to have better sprint speed than the batsmen while demonstrating maximal repeated sprints [2].

- It is necessary for the batsmen to have sprint speed as they have positional importance in the game ${ }^{[2]}$.

- There is limited evidence that works on repeated sprint ability and Lower limb power in amateur cricket batsmen hence there is a need to conduct this study.

\section{Review of literature}

1. Bravo DF, Impellizzeri FM, Rampinini E, Castagna C, Bishop D, Wisloff U. Sprint vs. interval training in football. (2007) conducted the study to compare the effects of high intensity aerobic interval training and RSA training on aerobic and anaerobic physiological component in male football players. By using an intervention of 12 session's sessions of 3 sets of $640-\mathrm{m}$ maximal shuttle sprints $(\sim 720 \mathrm{~m}$ per session without recovery) with $20 \mathrm{~s}$ of passive recovery between sprints and $4 \mathrm{~min}$ of passive recovery between sets. The shuttle sprints consist of all-out sprints (40m) with 180 degree direction change every $10 \mathrm{~m}$ (first 6 training sessions) or every 20m (remaining 6 training sessions)

2. Buchheit M, Mendez-Villanueva A, Quod M, Quesnel T, Ahmaidi S. - Improving acceleration and repeated sprint ability in well-trained adolescent handball players: speed versus sprint interval training. (2010) Conducted this study to compare sprint and agility with 
sprint interval training on acceleration and repeated sprint ability in trained male handball players. Method trained for 4 weeks. Repeated sprint ability (RSA) test was used to measure repeated sprint ability in the players.

3. Johnstone JA, Ford PA. Physiologic profile of professional cricketers. (2010) Conducted the study to study the physiological profile of professional cricketers and positional difference. The study concludes that the running speed in batsmen decreases in a moderate manner when compared to bowlers. Due to positional importance, batsmen find sprint speed necessary

4. Robert G. Lockie, Matthew D. Jeffriess \& Samuel J. Callaghan (2012) Exercise and Sport Science Department, School of Environmental and Life Sciences, University of Newcastle, Ourimbah, AUSTRALIA conducted a study on running velocity during run a three.

5. Kubal S, Padwal D. The effect of balance training on agility in young cricketers. (2013) Conducted the study to determine balanced training on agility. 66 young cricket players were selected who have undergone training twice a year and had no previous muscular skeletal injury. Players who had sprained and fractured or soft tissue injury over the last six to twelve months were excluded from the study. Also players with undiagnosed pain were excluded.

6. Turner AN, Stewart PF. Repeat sprint ability. Strength \& Conditioning Journal. (2013) Conducted the study to conclude RSA is the ability of an athlete to recover and maintain maximum efforts during subsequent sprints. Often trained and measured via high intensity sprints.

7. Sedeaud A, Marc A, Marck A, Dor F, Schipman J, Dorsey M, Haida A, Berthelot G, Toussaint JF. BMI, a performance parameter for speed improvement (2014) conducted the study to investigate the association between anthropometric characteristics and performance in all track and field running events, and $\mathrm{BMI}$ as relevant performance indicator.

8. Christie CJ, Elliot A, Pote L, Steenekamp T, Billaut F, Noakes TD. (2017) Effect of expertise on pacing strategies and sprint performance in batsmen. Concluded that skilled batsmen performed better under conditions of uncertainty, compared with their less skilled counterparts, which closely reflect actual scenarios of training and competition. This could indicate the strong presence and influence of the skilled batsmen's subconscious control based predominantly on experience with a task of an unknown duration. Through previous experience, the selection of more optimal pacing strategies may be established. Less skilled batsmen may not have sufficient accurate references to draw from due to their lack of exposure to the specific task which is reflected in their performance.

\section{Aim}

To study the effect of sprint interval training on repeated sprint ability \& lower limb power in amateur cricket batsmen at the end of 4 weeks.

\section{Objective}

1. To find the effect of sprint interval training on RSA using repeated sprint ability test in amateur cricket batsmen at the end of 4 weeks.
2. To find the effect of sprint interval training on lower limb power using standing long jump test in amateur cricket batsmen at the end of 4 weeks.

3. To find the effect of conventional exercise on RSA using repeated sprint ability test in amateur cricket batsmen in control group at the end of 4 weeks.

4. To find the effect of conventional exercise on lower limb power using standing long jump test in amateur cricket batsmen in control group at the end of 4 weeks.

5. To compare experimental and control group at the end of 4 weeks.

\section{Hypothesis}

- Null hypothesis

- $\quad H(0)$ - There will be no significant effect of sprint interval training on Repeated Sprint Ability \& lower limb power in amateur cricket batsmen by the end of 4 weeks.

- Alternate hypothesis

- $\quad$ H (1) - There will be significant effect of sprint interval training on Repeated Sprint Ability in amateur cricket batsmen by the end of 4 weeks.

- $\quad \mathrm{H}(2)$ - There will be significant effect of sprint interval training on lower limb power in amateur cricket batsmen by the end of 4 weeks.

- $\quad$ H (3) - There will be significant effect of sprint interval training on RSA and lower limb power both in amateur cricket batsmen by the end of 4 weeks.

- $\quad H(4)$ - There will be significant effect of conventional exercise on RSA in amateur cricket batsmen at the end of 4 weeks.

- $\quad \mathrm{H}(5)$ - There will be significant effect of conventional exercise on lower limb power in amateur cricket batsmen at the end of 4 weeks

- $\quad H(6)$ - There will be significant effect of conventional exercise on RSA and lower limb power both in amateur cricket batsmen by the end of 4 weeks.

\section{Methodology}

- Study design: Pre and Post experimental study with control group

- Study population: Male Amateur cricket batsmen (1520 years) ${ }^{[7]}$

- Sample size: 34

- Study settings: Cricket training centers in and around the city.

- Sampling method: Purposive

- Study duration: 6 months

- Intervention duration: 4weeks.

\section{Materials}

- Pen

- Paper

- Cone

- Case sheet

- Measuring tape

- Hand handles stop watch.

\section{Criteria}

Inclusion

- Male Amateur cricket batsmen age (15-20 years $)^{[7]}$

- Players playing from minimum 2 years ${ }^{[18]}$.

- Players practicing minimum 4 times every week ${ }^{[16]}$.

- $\quad$ Normal BMI (18-25) ${ }^{[12]}$ 
- Standing long jump score average \& above $(176 \mathrm{~cm}$ $186 \mathrm{~cm}$ )

\section{Exclusion}

- Recent fractures of lower limb within the past 6 months [18].

- Undiagnosed lower limb pain ${ }^{[18]}$.

- Players with any lower limb reconstructive surgery within the past two years.

- Any unresolved musculoskeletal disorders that constrain player to take part in sports.

- Any soft tissue injury in past 6 months like (ankle sprain, hamstring strain, etc. ${ }^{[18]}$

- Pathological conditions of heart and lungs like (hypertension, asthma, bronchitis, cognitive disorder, etc.) ${ }^{[19]}$

- Any neurological conditions like (hemiplegia, paraplegia, neuropathy, cognitive conditions, etc) ${ }^{[19]}$.

\section{Procedure}

- The study began with presentation of synopsis to the ethical committee of P.E.S Modern College of Physiotherapy.

- Ethical clearance acquired from the ethical committee.

- Cricket training centers in and cross the city were visited.

- Subjects were selected on the basis the inclusion and exclusion criteria.

- A written consent and ascent forms were taken.

- Participants were divided into two groups odd and even basis.

- Pre measure of RSA and standing long jump test was done for both groups. Group A was given sprint interval training and Group B continued with their regular training for 4 weeks. Post measure of RSA and Standing long jump test was done.

- The collected data was analyzed statistically and conclusion was drawn.

\section{Protocol}

For interventional group (A).

- Warm up exercise $10 \mathrm{mins}$.

- Which included, ankle rotations, high knees, leg swing sideways, marching, slow running 10 reps.

- $\quad$ Sprint Intervel Training (SIT) - the training consisted of 12 sessions of 3 sets of 6, 40-m maximal shuttle sprints ( 720m per session without recovery) with $20 \mathrm{~s}$ of passive recovery between sprints and $4 \mathrm{~min}$ of passive recovery between sets.

- The shuttle sprints included all-out sprints (40m) along with 180 degree directional change at every $10 \mathrm{~m}$ for the first 6 training sessions and progression to change at every $20 \mathrm{~m}$ remaining 6 training sessions ${ }^{[14]}$.

- Cool down self-stretching 10 mins of Quadriceps, hamstring, gluteus, piriformus, gastro-soules.
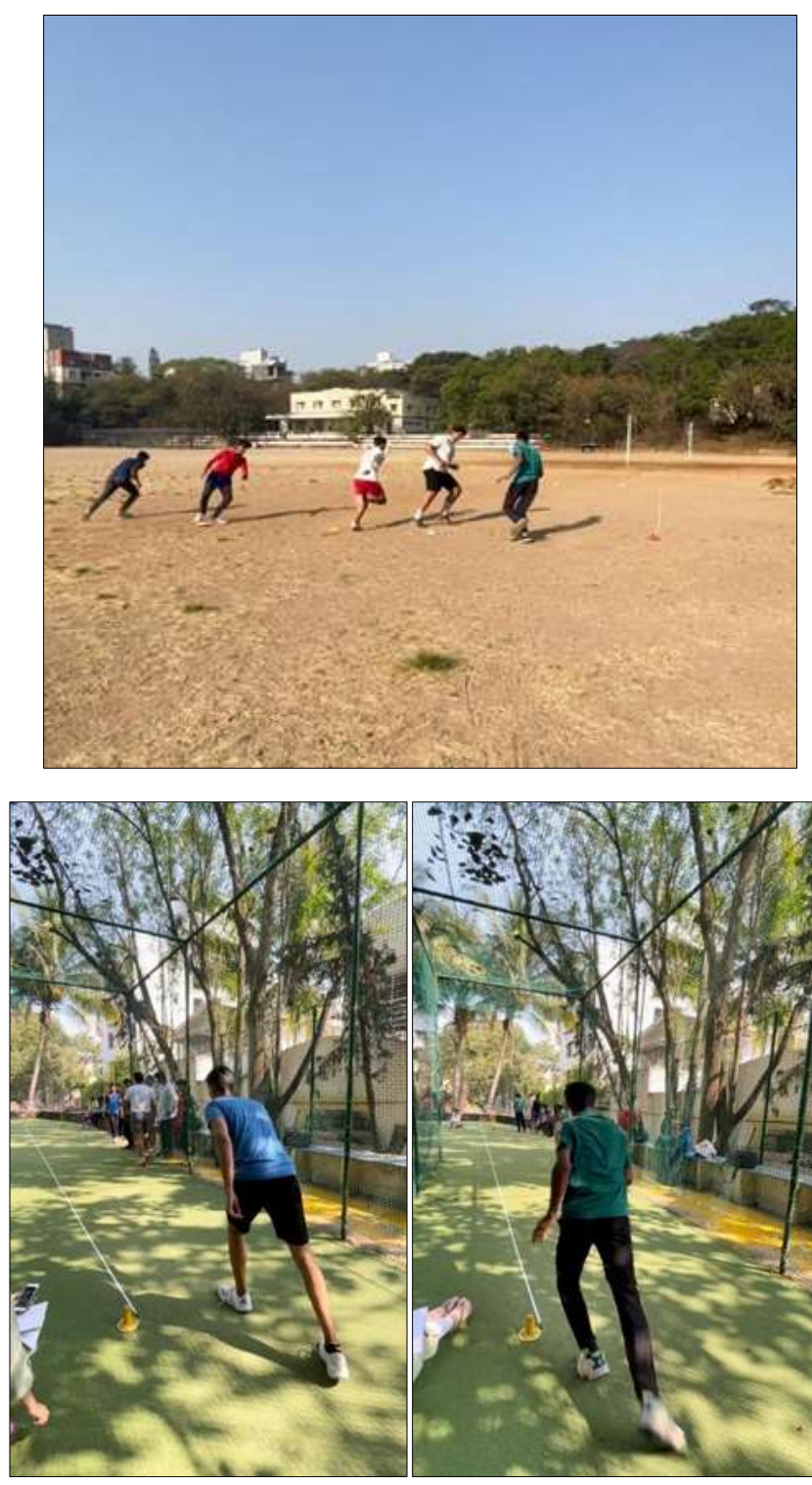

Fig 1: Repeated Sprint Ability

Table: Intervention Table

\begin{tabular}{|c|c|c|c|c|}
\hline Number of weeks. & Number of sessions per week & Number of sets per session & Number of repetitions per sets & $\mathbf{1 8 0}^{\circ}$ turn \\
\hline Week 1 & 3 sessions & 3 sets with 4 min recovery & 6 repetitions with 20 sec recovery & At every $10 \mathrm{~m}$ \\
\hline Week 2 & 3 sessions & 3 sets with 4 min recovery & 6 repetitions with 20 sec recovery & At every $10 \mathrm{~m}$ \\
\hline Week 3 & 3 sessions & 3 sets with 4 min recovery & 6 repetitions with 20 sec recovery & At every $20 \mathrm{~m}$ \\
\hline Week 4 & 3 sessions & 3 sets with 4 min recovery & 6 repetitions with 20 sec recovery & At every $20 \mathrm{~m}$ \\
\hline
\end{tabular}

\section{For conventional group (B)}

1. Warm up - ankle rotations, high knees, leg swing side ways, marching, slow running 10 reps.

- Core

- General fitness (long distance running, burpee, spinning)

- Strength training ( free weights, resistance band body weight)
- $\quad$ Speed ( Hurdles)

- Match-specific exercises (catching, hitting-specific target areas)

- Balance.

- Explosive power. ( body weight)

- Plyometics

- $\quad$ Agility. (Ladders)

- Visual training. 


\section{- $\quad$ Flexibility.}

2. Cool down self-stretching 10 mins of Quadriceps, hamstring, gluteus, piriformus, gastro-soules.

\section{Outcome measure}

\section{1) RSA: Repeated Sprint Ability ${ }^{[1]}$}

The RSA test involved six repetitions of maximal $2 \times 15-\mathrm{m}$ shuttle sprints (approximately 6s) departing every $20 \mathrm{~s}$ as has previously been discussed. During the 14-s recovery between sprints, participants were required to stand passively. Two seconds before starting each of the sprint, the subjects were asked to assume the start position as detailed for the $10-\mathrm{m}$ sprints and await the start signal. Strong verbal encouragement was provided to each participants during all sprints. This test was adapted from a previous running test which has been shown to produce reliable and valid estimates of RSA. Total Three scores were calculated for the RSA test: the best sprint time (RSA b; s), which is usually the first sprint; the mean sprint time (RSA $\mathrm{m} ; \mathrm{s})$ and the percent sprint decrement (\%Dec; \%) calculated as follows ${ }^{[24]}$.

(Mean sprint time/ best sprint time x 100) - $100^{24}$

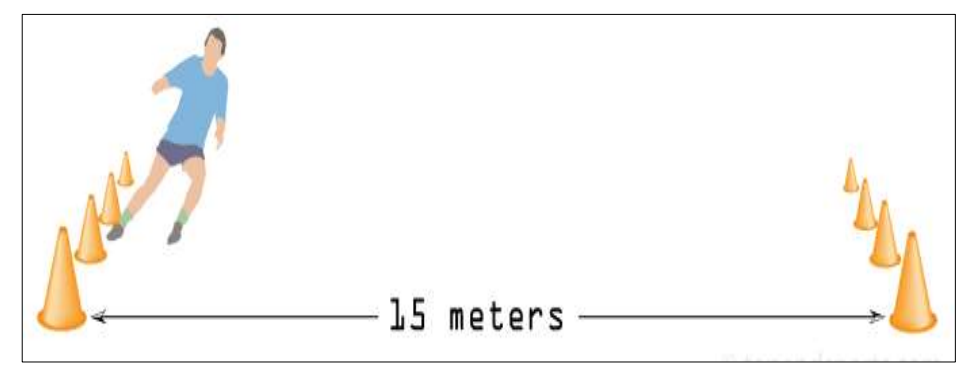

Fig 2: Repeated Sprint Ability Test

\section{2) Jumping power test ${ }^{[21]}$.}

The participant were told to stand behind the starting line and were instructed to push off vigorously and jump as far as possible. The participant had to land with the feet together and supposed to stay upright. Jump distance was measured from the takeoff line marked to the point where the back of the heel nearest to the takeoff line landed. A further attempt was allowed if the participants fell or touched the mat with other part of the body.

For the board jump, the score of the test represented the horizontal distance covered in a leap from semi- crouched position.

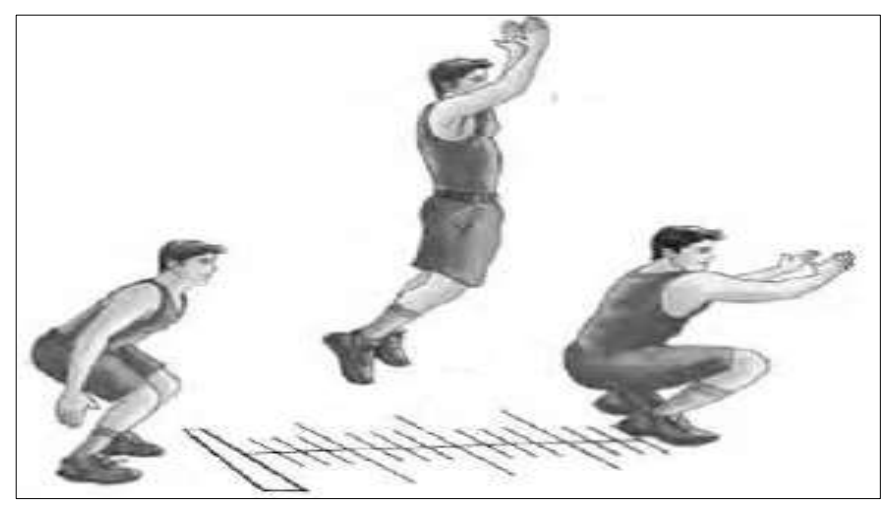

Fig 3: Jump Power Test
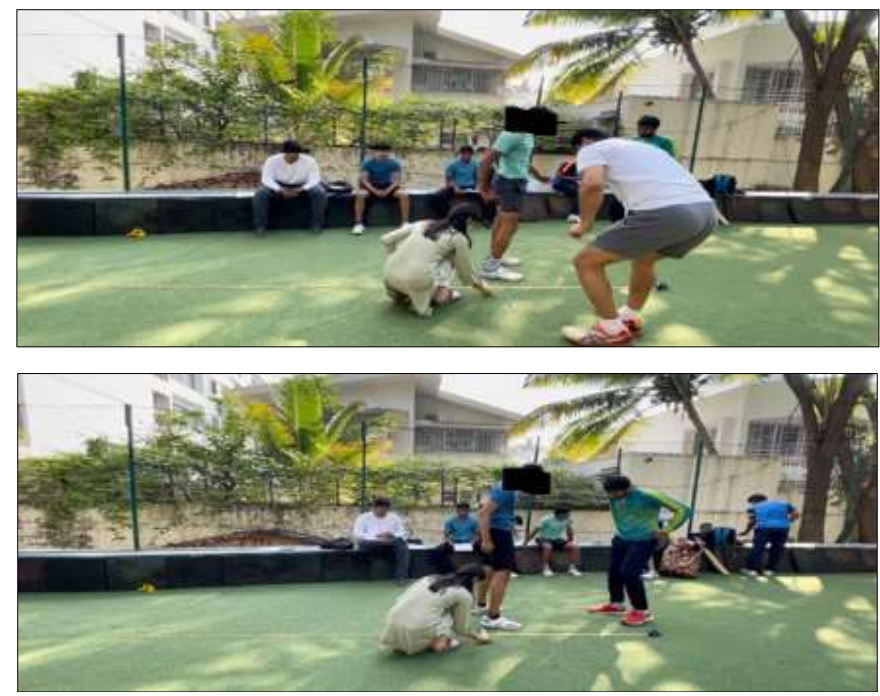

Fig 4: Jump Power Test at the actual site. 


\section{Data analysis and results}

The improvement in sprint decrement score was analysed using repeated sprint ability test. The improvement in lower limb power was analysed by using standing long jump test. The data entered was analysed with the help of primer software in stats, for checking effectiveness of sprint interval training in cricket batsmen, the data passed normality. Statistical Analysis was done for group A and group B using outcome measure repeated sprint ability and standing long jump test. Pre and post analysis for repeated sprint ability test and standing long jump test was done by paired $\mathrm{t}$ test by using in stat 3.10 software. Comparing repeated sprint ability test and standing long jump test was done by unpaired t test by using in stat 3.10 software.

\section{Interventional group}

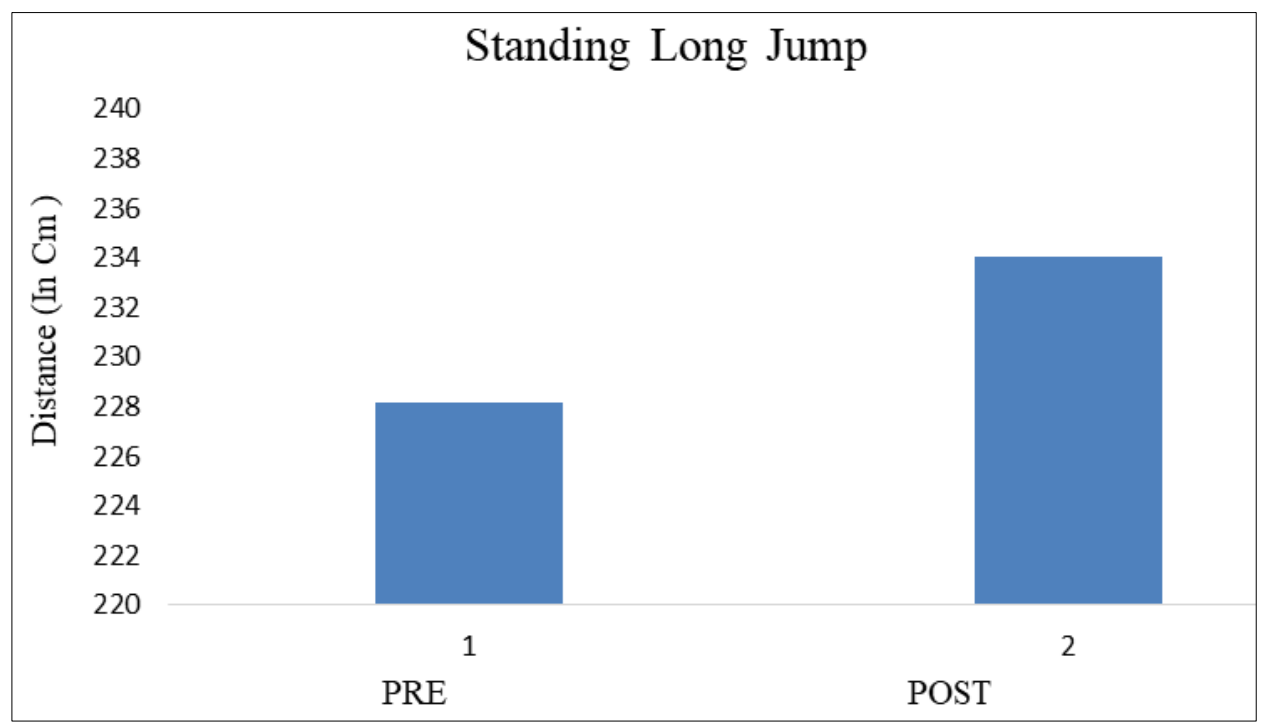

Graph 1: Pre and post jump power test results of interventional group

Table 1: Values of jump power test of interventional group

\begin{tabular}{|c|c|c|}
\hline Standing long jump & Mean & SD \\
\hline Pre & 228.18 & 32.030 \\
\hline Post & 234.06 & 31.614 \\
\hline T value & \multicolumn{2}{|c|}{ P value } \\
\hline $\mathrm{t}=9.017$ with 16 degrees of freedom. & P value is $<0.0001$, considered extremely significant \\
\hline
\end{tabular}

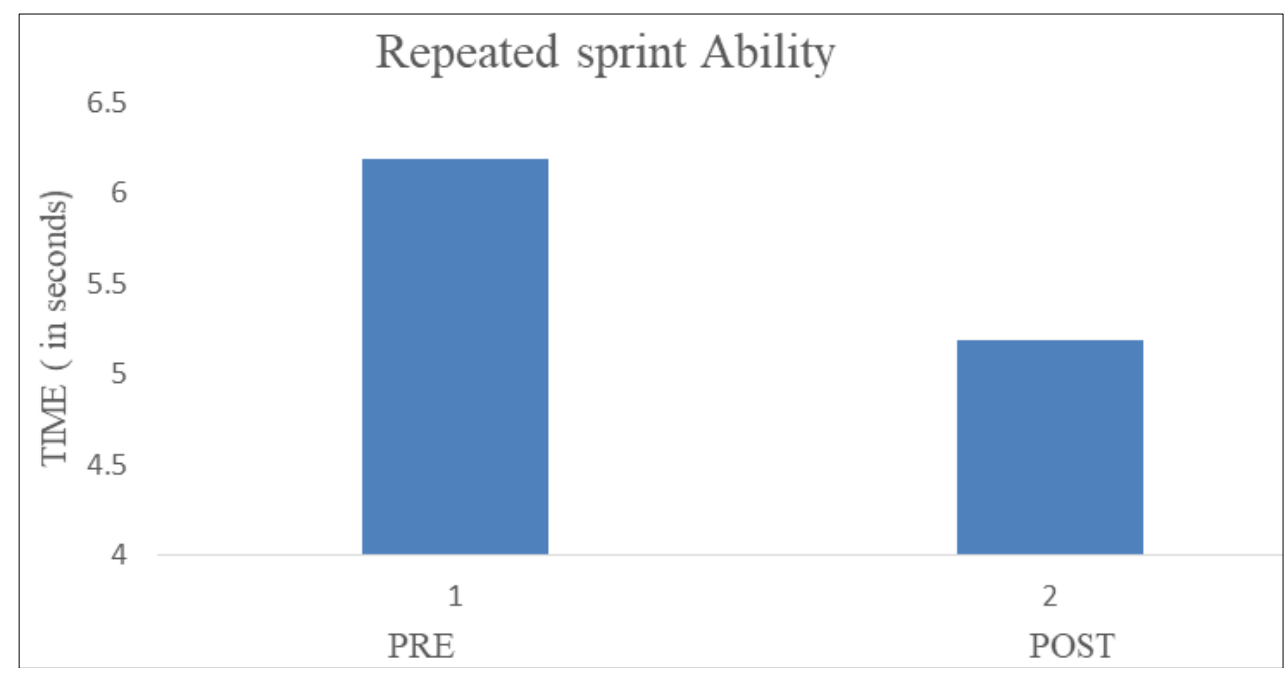

Graph 2: Pre and post Repeated Sprint Ability results of interventional group

Table 2: Values of Repeated Sprint Ability test for interventional group

\begin{tabular}{|c|c|c|}
\hline RSA & Mean & SD \\
\hline PRE & 6.193 & 1.463 \\
\hline POST & 5.186 & 1.608 \\
\hline \multicolumn{2}{|c|}{ T value } & \multicolumn{2}{c|}{ P value } \\
\hline $\mathrm{t}=5.085$ with 16 degrees of freedom. & P value is 0.0001, considered extremely significant. \\
\hline
\end{tabular}




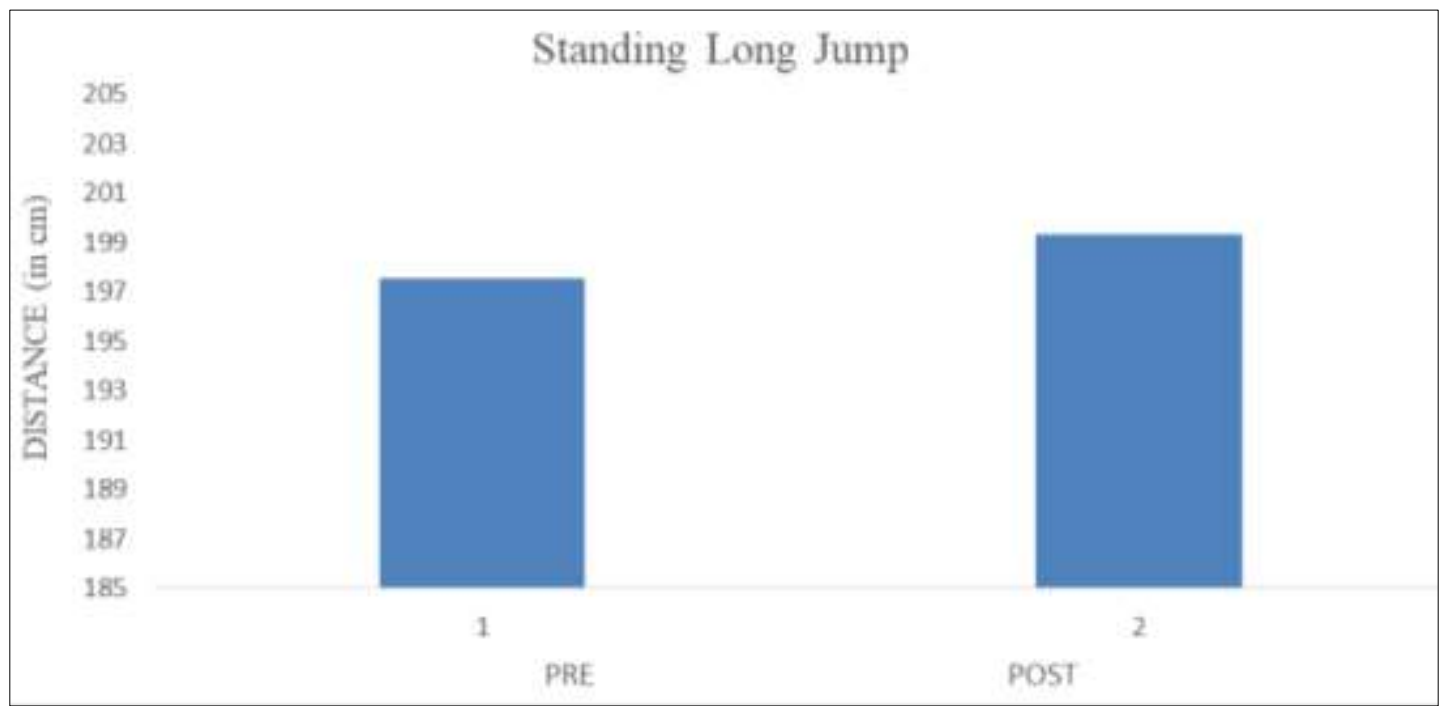

Graph 3: Pre and Post jump power test results of control group

Table 3: Values of jump power test of control group

\begin{tabular}{|c|c|c|}
\hline Standing long jump & Mean & SD \\
\hline Pre & 197.53 & 17.230 \\
\hline Post & 199.29 & 16.732 \\
\hline T value & \multicolumn{2}{|c|}{ P value } \\
\hline $\mathrm{t}=3.017$ with 16 degrees of freedom. & P value is 0.0082 , considered very significant. \\
\hline
\end{tabular}

\section{Repeated Sprint Ability}

7.5

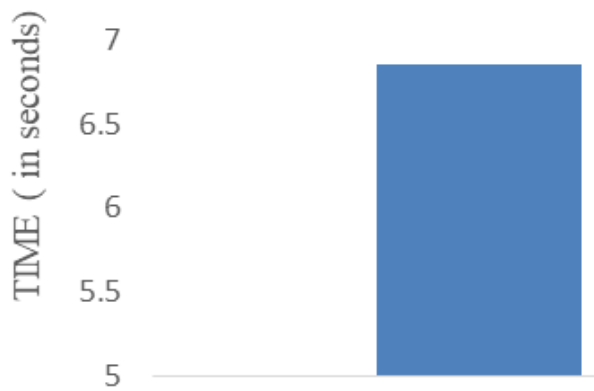

1

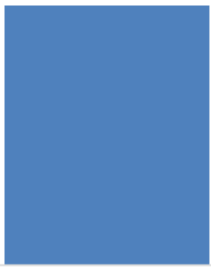

2

POST

Graph 4: Pre and Post results of repeated sprint ability of control group

Table 4: Values of repeated sprint ability of control group

\begin{tabular}{|c|c|c|}
\hline RSA & Mean & SD \\
\hline PRE & 6.855 & 2.682 \\
\hline POST & 6.549 & 0.8858 \\
\hline \multicolumn{2}{|c|}{ T value } & P value \\
\hline $\mathrm{t}=0.5741$ with 16 degrees of freedom. & P value is 0.5739, considered not significant. \\
\hline
\end{tabular}




\section{Data analysis between the groups}

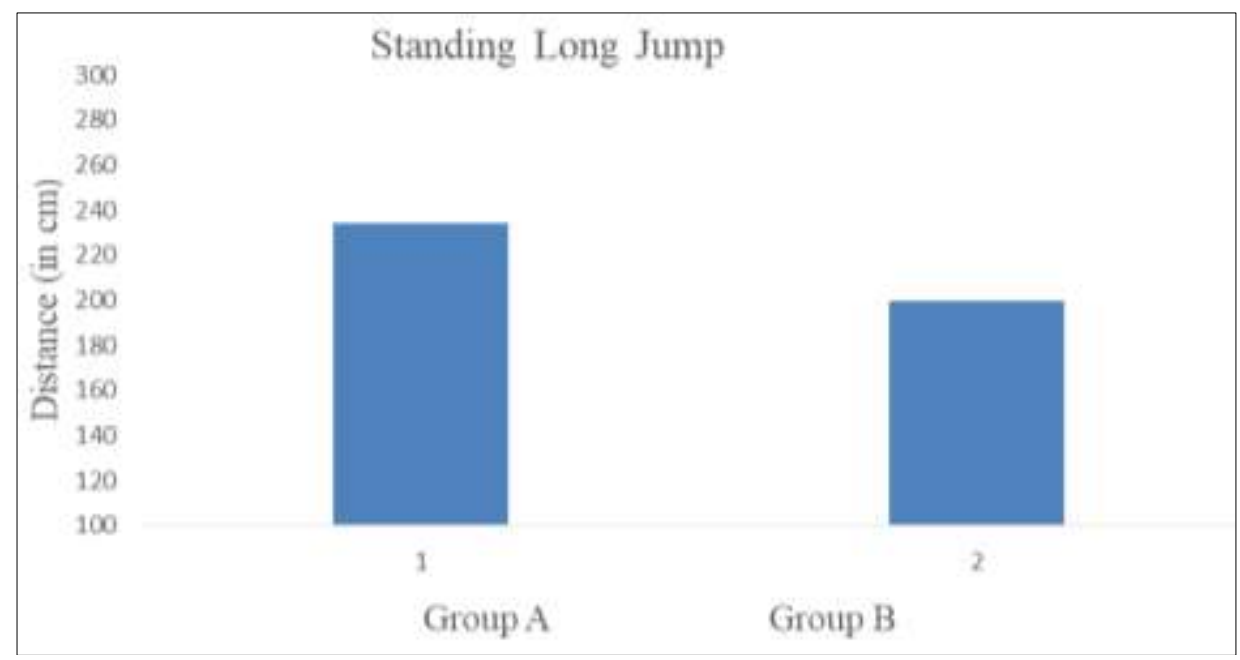

Graph 5: Comparison of Group A and Group B

Table 5: Values of Group A and Group B

\begin{tabular}{|c|c|c|}
\hline Group & Mean & SD \\
\hline $\mathrm{A}$ & 234.06 & 31.614 \\
\hline B & 199.29 & 16.732 \\
\hline \multicolumn{2}{|c|}{ T value } & P value \\
\hline \multicolumn{3}{|c|}{$\mathrm{t}=4.007$ with 32 degrees of freedom. P value is 0.0003 , considered extremely significant. } \\
\hline
\end{tabular}

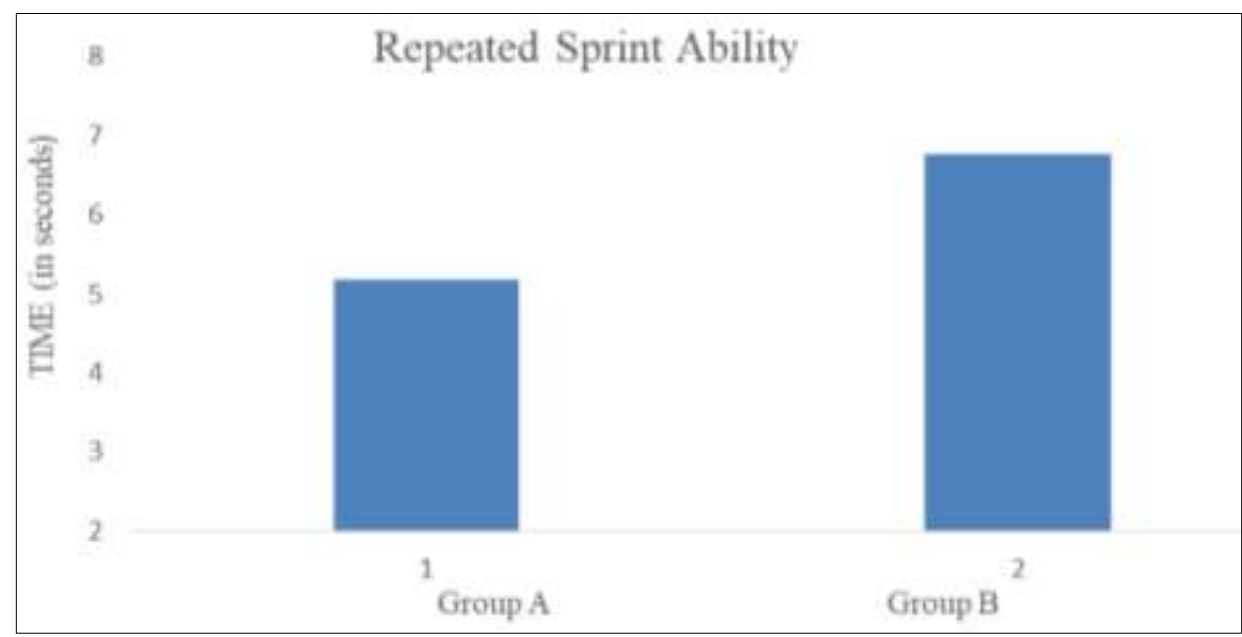

Graph 6: Comparison of Group A and Group B

Table 6: Values of Group A and Group B

\begin{tabular}{|c|c|c|}
\hline Group & Mean & SD \\
\hline A & 5.186 & 1.608 \\
\hline B & 6.549 & 0.8858 \\
\hline \multicolumn{2}{|c|}{ T value } & \multicolumn{2}{c|}{ P value } \\
\hline $\mathrm{t}=3.061$ with 32 degrees of freedom. & P value is 0.0044, considered very significant. \\
\hline
\end{tabular}

\section{Discussion}

The study was undertaken to determine Effectiveness of sprint interval training on Repeated Sprint Ability (RSA) \& lower limb power in amateur cricket batsmen at the end of 4 Weeks. Cricket is a sport which involves intermittent activities. Cricketers must be trained to run as quickly as possible over short distances and maintain the speed throughout. Repeated sprint ability is considered a significant attribute in cricket, the ability to run is an essential skill for batsmen as running between the wickets can increase the scoring rate in a match. Sprint interval training has been shown to improve neural adaptations and increase muscle $\mathrm{Cr}$ and $\mathrm{CK}$ levels, with simultaneous improvements in muscular oxidative capacity, muscle glycogen content, as well as enhanced muscle buffer capacity over a short span of time ${ }^{[9,10]}$, which are all factors likely to benefit the maintenance of high-intensity exercise $[8,1]$. The study by Jonathan Taylor the effect of repeated sprint training of field based fitness measures, stated that the success of repeated sprint training has garnered increased attention because of its potential to impact both strength/ power and endurance in team sports. The result of this 
analysis shows a clear advantageous effect of this mode of training on important elements of fitness relevant to team sports. Also, some more work to operate the protocols in order to achieve desired results with respect to power, speed, and endurance is recommended.

The study by Sane Malone Can the workload-injury relationship be moderated by improved strength, speed and repeated-sprint qualities? Indicates that well developed lower body strength, RSA and speed were linked to better and improved tolerance to higher workloads and reduced probability of injury in team sport players and athletes. When compared to a lower performance group, those with higher strength, faster speed, and RSA were at a lesser risk of injury. Coaches should expose players to training protocols that improve these physical qualities to a modest injury risk within their group of players. The study was completed with an amateur group of players, and the findings are possibly to be useful for coaches of sub elite players.

Ferrari et al., in their discussion of study of sprint vs. interval training in football players stated that sprint interval training was used in improving aerobic and anerobic power. only SIT induced a greater increase in RSA. Improving RSA can be related to anaerobic power. The conclusion was backed by monitored in decrease of RSA mean. They also said anerobic metabolism is the main determinated of RSA and can be improved with SIT ${ }^{[14]}$.

Sanne et al., on basketball players in their discussion stated that the positive correlation between RSA and lower body power indicates that a better lower body power is related to a better RSA ${ }^{[26]}$.

Martin Buchheit, in his study on handball players stated that in well-trained handball players, $4 \mathrm{wk}$. of SIT is likely to have a moderate impact on sprint decrement score. Similarly in our study sprint interval training has found to be positively imporving sprint decrement score as well as lower limb power.

In the study done by Sanjeev kumar sharma stated that plyometric training can be more beneficial and effective than free mobility exercise training program and have positive effect on long jump performance.

Similarly in our study we could see significant improvement of strengthen training and plyometric training on the standing long jump. There was a mild difference in sprint decrement score but was not enough significant statistically. Players in conventional group had vigorous strengthen training and functional training this helped players to benefit in the standing long jump. The players targeted lower limb strength training program one a week which included high intensity jumping, weighted squats and plyometric training. Plyometric training has also shown to be an instant method to increase lower limb power. Conventional group had mild change in decrement score. This could be due to increase in the lower limb power.

\section{Conclusion}

This study concludes that Sprint Interval Training is more effective than conventional exercises in improving the repeated sprint ability and lower limb power in amateur cricket batsmen by the end of 4 weeks.

\section{Limitation}

1. This study was done using small sample size due to covid situations.
2. Grading of Repeated Sprint Ability not included.

\section{Future scope of study}

1. Further studies with larger sample size can be done.

2. Agility can be assessed by using the same protocol.

3. Carry over effect can be seen with progressing the duration and difficulty of training.

4. This protocol can be used in other sports consisting intermittent activities.

5. The study can be carried out with female participants.

6. This protocol can be compared with other different protocols.

\section{Clinical implications}

1. This protocol be used in cricket training for improving sprinting ability to efficiently run in brief bouts especially between the wickets in cricket players and thereby increasing power of lower limb.

2. This protocol can be used any sports that needs intermittent running and lower limb power.

\section{References}

1. Buchheit M, Mendez-Villanueva A, Quod M, Quesnel $\mathrm{T}$, Ahmaidi S. Improving acceleration and repeated sprint ability in well-trained adolescent handball players: speed versus sprint interval training. International Journal of Sports Physiology and Performance 2010;5(2):152-64.

2. Johnstone JA, Ford PA. Physiologic profile of professional cricketers. The Journal of Strength \& Conditioning Research 2010;24(11):2900-7.

3. Turner AN, Stewart PF. Repeat sprint ability. Strength \& Conditioning Journal 2013;35(1):37-41.

4. Iaia FM, Fiorenza M, Larghi L, Alberti G, Millet GP, Girard O. Short-or long-rest intervals during repeatedsprint training in soccer? PloS one 2017, 12(2).

5. Kumar A, Kathayat LB, Kadam G. Relationship among speed, power and fatigue index of cricket players. Journal of Exercise Science and Physiotherapy 2015;11(1):11.

6. Christie CJ, Elliot A, Pote L, Steenekamp T, Billaut F, Noakes TD. Effect of expertise on pacing strategies and sprint performance in batsmen. Journal of science and medicine in sport 2018;21(5):513-7.

7. Ranjan P, Pruthviraj R, Bhatbolan S, Sriraghunath S, Paul Daniel VK, Nisha AD. Prevalence of scapular dysfunction in young amature cricketers with or without shoulder problem.

8. Gibala MJ, McGee SL. Metabolic adaptations to shortterm high-intensity interval training: a little pain for a lot of gain? Exercise and sport sciences reviews 2008;36(2):58-6.

9. Gibala MJ, Little JP, Van Essen M, Wilkin GP, Burgomaster KA, Safdar A et al. Short-term sprint interval versus traditional endurance training: similar initial adaptations in human skeletal muscle and exercise performance. The Journal of physiology 2006;575(3):901-11.

10. Burgomaster KA, Howarth KR, Phillips SM, Rakobowchuk M, MacDonald MJ, McGee SL et al. Similar metabolic adaptations during exercise after low volume sprint interval and traditional endurance training in humans. The Journal of physiology 2008;586(1):151-60. 
11. Buchheit M, Mendez-Villanueva A, Delhomel G, Brughelli M, Ahmaidi S. Improving repeated sprint ability in young elite soccer players: repeated shuttle sprints vs. explosive strength training. The Journal of Strength \& Conditioning Research 2010;24(10):271522.

12. Sedeaud A, Marc A, Marck A, Dor F, Schipman J, Dorsey $\mathrm{M}$ et al. BMI, a performance parameter for speed improvement. PloS one 2014, 9(2).

13. Mero A, Komi PV, Gregor RJ. Biomechanics of sprint running. Sports medicine 1992;13(6):376-92.

14. Bravo DF, Impellizzeri FM, Rampinini E, Castagna C, Bishop D, Wisloff U. Sprint vs. interval training in football. International journal of sports medicine 2008;29(08):668-74.

15. Lockie RG, Jeffriess MD, Callaghan SJ. Running velocity during the run-a-three in experienced cricketers. Serbian Journal of Sports Sciences 2012, $6(3)$.

16. Talupuru PK, Kulandaivelan S, Haripriya U, Singh V. Effect of BMI on hand grip strength in elite cricket players. Int J Physiother Res 2016;4(5):1696-700.

17. Petersen CJ, Pyne D, Dawson B, Portus M, Kellett A. Movement patterns in cricket vary by both position and game format. Journal of sports sciences 2010;28(1):4552.

18. Kubal S, Padwal D. The effect of balance training on agility in young cricketers. International Journal of Science and Research (IJSR) 2016;5(10):485-92.

19. Ramachandran S, Paul J, Cyrus BE, Kumar PJ. Effects of core stability training on speed of search engine: running in male cricket players www. ijmaes. org.

20. Buchheit M, Millet GP, Parisy A, Pourchez S, Laursen PB, Ahmaidi S. Supramaximal training and postexercise parasympathetic reactivation in adolescents. Medicine \& Science in Sports \& Exercise 2008;40(2):362-71.

21. Essentials of exercise physiology by Victor Katch L, Willam D McArdle, Frank I. Katch ( ${ }^{\text {th }}$ edition) chapter 6 , chapter 7, chapter 13 .

22. Mero A, Komi PV, Gregor RJ. Biomechanics of sprint running. Sports medicine 1992;13(6):376-92.

23. Pote L, Christie CJ. Strength and conditioning practices of university and high school level cricket coaches: a South African context. The Journal of Strength \& Conditioning Research 2016;30(12):3464-70.

24. Pareja-Blanco F, Suarez-Arrones L, Rodríguez-Rosell D, López-Segovia M, Jiménez-Reyes P, Bachero-Mena $\mathrm{B}$, et al. Evolution of Determinant Factors of Repeated Sprint Ability. Journal of Human Kinetics 2016;54(1):115-26.

25. Herridge R, Turner A, Bishop C. Monitoring Changes in Power, Speed, Agility, and Endurance in Elite Cricketers During the Off-Season Period. Journal of Strength and Conditioning Research 2020;34(8):228593.

26. Te Wierike SC, De Jong MC, Tromp EJ, Vuijk PJ, Lemmink KA, Malina RM et al. Development of Repeated Sprint Ability in Talented Youth Basketball Players. Journal of Strength and Conditioning Research 2014;28(4):928-34. 